\title{
On the production of intense magnetic fields
}

\section{Prof. Stefan}

To cite this article: Prof. Stefan (1888) On the production of intense magnetic fields, Philosophical Magazine Series 5, 25:155, 322-323, DOI: 10.1080/14786448808628194

To link to this article: http://dx.doi.org/10.1080/14786448808628194

$$
\text { 册 Published online: } 29 \text { Apr } 2009 .
$$

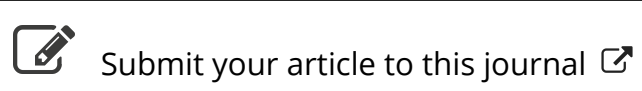

\footnotetext{
Џ Article views: 4
}

Q View related articles $\sqsubset$ 
described from Snead, near Bishop's Castle, where fragments of basic glass are imbedded in a tuff of Ordovician age.

In conclusion, the well-known variolite of the Durance was cited as a rock of basic character, comparable, in its perlitic and spherulitic structures with the acid " pyromerides," both types having alike suffered from secondary devitrifiction.

4. "Appendix to Mr. A. T. Metcalfe's paper 'On Further Discoveries of Vertebrate Remains in the Triassic Strata of the South Coast of Devonshire, between Budleigh Salterton and Sidmouth."" By H. J. Carter, Esq., F.R.S.

\section{Intelligence and Miscellaneous Articles.}

\section{ON THE PRODUCTION OF INTENSE MAGNETIC FIELDS. BY PROF. STEFAN.}

THE maximum magnetizing force which cylindrical iron cores of 1 an electromagnet can exert between plane pole-pieces standing opposite each other is $4 \pi \mu$, in which $\mu$ is the greatest magnetic moment which the unit volume of iron can assume. If we take $\mu=1700$ absolute units, $4 \pi \mu=213600$. This value is the more nearly attained, the smaller the distance of the pole-pieces.

The action which the iron cores exert in the centre of the field can be increased without limitation of its length, if the terminal faces of the pole-pieces are made of another shape. This increase attains the greatest value if the ends of the cores have the shape of truncated cones, so that the generating lines of the two conical surfaces pass through the centre of the field, and form with its axis an angle whose tangent is $\sqrt{ } 2$, that is an angle of $54^{\circ} 44^{\prime}$.

The magnitude of the force is then expressed by the formula

$$
\mathrm{H}=4 \pi \mu\left(0 \cdot 289+0 \cdot 886 \log \frac{d}{a}\right),
$$

where $d$ is the diameter of the iron core, $a$ the length of the field. The formula gives an increase of $\mathbf{H}$ to any large values. In practice this is unimportant, for with the slow increase of the logarithms compared with that of the numbers, conditions of construction result which cannot be carried out. If $\mathrm{H}=8 \pi \mu$, $d$ must be taken $=85 a$.

For certain optical investigations it is necessary to perforate the iron cores. For such cores with plane pole-pieces the principle no longer holds that the magnetic field is the more intense the nearer the pole-surfaces. The magnetic force in the centre of the field 
attains its greatest value if the distance of the pole-surfaces $a$ satisfies equation

$$
a^{2}=d_{0}^{2} \cdot \frac{n^{\frac{4}{3}}}{n^{\frac{2}{3}}+1}
$$

in which $d$ is the diameter of the perforation, $n$ the number which indicates by how much the diameter of the iron core is greater than that of the perforation.

The perforation of the iron core always produces a great deformation of the magnetic field. The intensity decreases considerably from the centre towards the end of the field. Between plane polepieces the force at the end of the field is smaller than the half of the force in the centre. Iron cores with conical ends of the form just prescribed have the advantage of a greater intensity in the centre, and at the same time a smaller decrease of the force towards the end of the field.-Wiener Berichte, Feb. 9, 1888.

\section{EXPERIMENTS ON THAT FORM OF THE DISCHARGE OF ELECTRICITY KNOWN AS ST. ELMO'S FIRE.}

BY A. V. OBERMAYER.

The experiments described in the paper show that the positive brushes are reddish white in the stem, with riolet radiating branches. The stems which project into the brush are at angles which may reach $90^{\circ}$, and the rays may attain a length of 6 to 7 centim. Further, that the negative brushes which verge into violet are always so fine that individual rays can no longer be distinguished, that these brushes standing on a luminous point show an angle of aperture of less than $90^{\circ}$, and that the length of the brush is always under 1 centim.

In discharges from positive surfaces, for instance from clothes, these appear covered with fine rays of a length up to 3 centim., which are like the hairs of a fur.

Discharges from similar negative surfaces consist of a phosphorescent glow-light which is in continual motion, and is traversed by dark spaces.

The falls in potential necessary for the production of such a brush-discharge decreases with the distance through which the discharge takes place. In volts per centimetre this fall was approximately :

At 5 centin. distance 6000 volts per centim.

$\begin{array}{llll}15 & \quad " & 4000 & \\ 30 & & \end{array}$

